\title{
Cell Culture-Based Biosynthesis
}

National Cancer Institute

\section{Source}

National Cancer Institute. Cell Culture-Based Biosynthesis. NCI Thesaurus. Code C112922.

A process that synthesizes a material of interest using cell culture techniques. 